\title{
Interactions between soil- and dead wood-inhabiting fungal communities during the decay of Norway spruce logs
}

\author{
Raisa Mäkipää ${ }^{1}$, Tiina Rajala ${ }^{1,4}$, Dmitry Schigel ${ }^{2}$, Katja T Rinne ${ }^{1}$, Taina Pennanen ${ }^{1}$, \\ Nerea Abrego $^{3}$ and Otso Ovaskainen ${ }^{2,3}$ \\ ${ }^{1}$ Natural Resources Institute Finland (Luke), Helsinki, Finland; ${ }^{2}$ Department of Biosciences, University of \\ Helsinki, Helsinki, Finland and ${ }^{3}$ Department of Biology, Centre for Biodiversity Dynamics, Norwegian \\ University of Science and Technology, Trondheim, Norway
}

\begin{abstract}
We investigated the interaction between fungal communities of soil and dead wood substrates. For this, we applied molecular species identification and stable isotope tracking to both soil and decaying wood in an unmanaged boreal Norway spruce-dominated stand. Altogether, we recorded 1990 operational taxonomic units, out of which more than 600 were shared by both substrates and 589 were found to exclusively inhabit wood. On average the soil was more species-rich than the decaying wood, but the species richness in dead wood increased monotonically along the decay gradient, reaching the same species richness and community composition as soil in the late stages. Decaying logs at all decay stages locally influenced the fungal communities from soil, some fungal species occurring in soil only under decaying wood. Stable isotope analyses suggest that mycorrhizal species colonising dead wood in the late decay stages actively transfer nitrogen and carbon between soil and host plants. Most importantly, Piloderma sphaerosporum and Tylospora sp. mycorrhizal species were highly abundant in decayed wood. Soil- and wood-inhabiting fungal communities interact at all decay phases of wood that has important implications in fungal community dynamics and thus nutrient transportation.
\end{abstract}

The ISME Journal (2017) 11, 1964-1974; doi:10.1038/ismej.2017.57; published online 21 April 2017

\section{Introduction}

Fungi have essential roles in forest ecosystem functioning. Saprotrophic fungi are key regulators of nutrient recycling and the main agents decomposing organic matter (Boddy et al., 2008), and mycorrhizal fungi are of crucial importance in facilitating nutrient uptake for plants (Smith and Read, 2008). Therefore, fungal communities affect the rate of decomposition, nutrient cycling and resiliency of the ecosystem functioning (Hättenschwiler et al., 2005; Gessner et al., 2010; Valentín et al., 2014). Mycorrhizal fungi are mainly found in soil where their mycelia is associated to plant roots, and saprotrophic fungi inhabit both soil and dead wood, where decomposable organic resources are available. Saprotrophic fungal communities from soil and woody substrates are qualitatively different, as fungi utilising wood and fungi decomposing the organic matter in soil employ

Correspondence: R Mäkipää, Natural Resources Institute Finland (Luke), Latokartanonkaari 9, FI-00790 Helsinki, Finland.

E-mail: Raisa.Makipaa@luke.fi

${ }^{4}$ Deceased.

Received 20 December 2016; revised 18 February 2017; accepted 3 March 2017; published online 21 April 2017 different ecophysiological strategies adapted to the characteristics of each substrate (Watkinson et al., 2006). As a result of the fungal decomposition process, dead wood resources eventually become soil, and soil- and wood-inhabiting fungal communities converge. Soil- and wood-inhabiting fungal communities are more similar in the advanced decay stages of dead wood (for example, Renvall, 1995; Rajala et al., 2012; Ottosson et al., 2014), yet the timing of the species exchange and its consequences in nutrient cycling and fungal community dynamics remain poorly understood.

Fungal communities in soil and wood have typically been studied separately (Buée et al., 2009; Kubartová et al., 2012; Ovaskainen et al., 2013), but several studies have noted the presence of wooddecaying fungi in soil (for example, Lindahl et al., 2007) and conversely the presence of mycorrhizal fungi in wood (Tedersoo et al., 2003; Rajala et al., 2012, 2015). Indeed, many mycorrhizal fungi are also able to colonise woody substrates that are heavily decayed and in contact with the soil surface (Tedersoo et al., 2003), whereas many soil saprotrophs are able to colonise wood (Rayner and Boddy, 1988). Some mycorrhizal species even tend to produce fruiting bodies more often in wood than 
they do in soil (for example, Piloderma, Tomentella and Tylospora species) (Stokland et al., 2012). The mycorrhizal species which are able to colonise wood have the ability to obtain mineral nutrients through decomposition, in addition to their primary strategy of translocating nutrients to plant roots (Lindahl and Tunlid, 2015). Conversely, some wood-decaying fungi (in particular cord-forming basidiomycetes) are able to grow out of the wood and forage for new resources in soil (for example, Armillaria, Hypholoma and Phanerochaete species; Boddy, 1993, 1999).

Even if most occurrences of mycorrhizal fungi in dead wood have been reported for the last decay phases of dead wood (Renvall, 1995; Rajala et al., 2012, 2015; Ottosson et al., 2014), the colonisation of dead wood by mycorrhizal fungi might happen in earlier phases of wood decay. For instance, some Tomentella species have been found to occur more often in dead wood in intermediate decay phases than in late decay phases (cf. Edman and Jonsson, 2001; Abrego and Salcedo, 2013). As another example of species exchange between soil and wood in early phases of decay, the cord-forming Armillaria species extend their mycelia from dead wood through soil and colonise living trees (Ferguson et al., 2003).

The exchange of fungal species between wood and soil has important implications in forest nutrient cycling. As shown by Mahmood et al. (2003), the mycorrhizal activity of some fungal species is stimulated when they colonise woody substrates that ultimately improves plant growth. The nutrients accumulated in wood resources are reallocated in soil by wood-decaying saprotrophs, which can extend their mycelial networks many metres from where the wood pieces are located (Boddy and Watkinson, 1995). Conversely, wood-decaying fungi with rhizomorphs can translocate ${ }^{15} \mathrm{~N}$-enriched nitrogen from the forest floor to decaying logs, and thus fungi-mediated nitrogen transport from the soil can be a source of external nitrogen in decaying logs (Philpott et al., 2014). This additional nutritional income in dead wood might have important implications in the decomposition process, as the activity of saprotrophic fungi is stimulated when the nitrogen availability is enhanced (Bebber et al., 2011).

As fungal species colonise new habitats, they are exposed not only to a new abiotic environment, but also to a new biotic environment where other fungal species are utilising the same resources. Interspecific combative interactions occur commonly between fungi that share a given habitat and have similar nutrient requirements (Boddy, 2000; Wells and Boddy, 2002). Thus, the colonisation of soil by wood-decaying fungi (or wood by soil fungi) may influence the dynamics of the resident soilinhabiting fungal communities (or respectively wood-inhabiting communities). As a result of the fungal species exchange between soil and wood, either habitats can suffer from species loss (if the new colonisers are stronger competitors) or species gain (if the new colonisers have non-overlapping nutrient requirements, allowing coexistence).

Dead wood has drastically declined from forest ecosystems because of human forest-use activities (for example, Grove, 2001; Ranius et al., 2003; Kebli et al., 2012). Loss of dead wood has come along with a negative impact on wood-inhabiting fungal communities, notably with a decrease in species richness in heavily managed forests (Fridman and Walheim, 2000; Siitonen, 2001; Stokland et al., 2012; Peltoniemi et al., 2013). As explained above, dead wood is an important carbon and nutrient source in forest ecosystems (Laiho and Prescott, 2004), and possibly soils is an important fungal species reservoir for wood and vice versa. Nevertheless, to our knowledge, the implications of the loss of dead wood in soil fungal communities have not been investigated.

The goal of this study was to analyse fungal succession in decaying wood and the relationship between wood- and soil-inhabiting fungal communities. We hypothesised that soil- and woodinhabiting fungal communities become more similar as dead wood decays, and that soil fungal communities are affected by the presence of decaying logs on the adjacent soil surface. We also hypothesised that when mycorrhizal fungi colonise dead wood, they transport ${ }^{15} \mathrm{~N}$ from soil to wood and when this happens, ${ }^{13} \mathrm{C}$ depletion is favoured in decaying wood. For assessing the fungal species exchange between soil and wood, we evaluated in which decay phase and by which species do wood- and soil-inhabiting fungal communities become similar. To evaluate the exchange between wood and soil fungi more locally, we also asked whether the wood communities are more similar to soil communities sampled right under the focal log than to soil communities sampled under other logs. To address these questions, we applied DNA extraction and 454 pyrosequencing to both soil and decaying wood in an unmanaged boreal Norway spruce-dominated stand. For testing our second hypothesis, we used stable isotope analyses aimed to identify potential transfer of nitrogen between soil and decaying wood.

\section{Materials and methods}

Study area and study design

The study was carried out in Rörstrand, a sprucedominated forest, located in Sipoo, southern Finland $\left(60^{\circ} 28^{\prime} \mathrm{N}, 25^{\circ} 12^{\prime} \mathrm{E}\right.$, altitude $65 \mathrm{~m}$ a.s.l., effective temperature sum $\left.1291^{\circ} \mathrm{C}\right)$. This forest is a fertile, mesic heath forest (Vaccinium myrtillus type according to Cajanders's classification (Hotanen et al., 2008)). The main study was carried out in a 4 ha unmanaged area, where the volumes of living and dead trees are 447 and $121 \mathrm{~m}^{3} \mathrm{ha}^{-1}$, respectively. For comparison, soil samples also were collected from four additional Norway spruce-dominated mature stands within $15 \mathrm{~km}$ distance from the main study 
site. The additional stands (Sipoo Rörstrand, Nikkilä, Nummenkylä and Lintumetsäntie) have otherwise the similar characteristics but are managed and therefore the amount of dead wood was marginal.

Altogether, 61 fallen Norway spruce trees (Picea abies L. Karst) were selected in the main study area as sample logs that were distributed equally into different decay classes (DC) (1-5) (see Mäkinen et al. (2006) for definition of DC). The locations of all sampled logs were mapped in $25 \times 25 \mathrm{~m}$ grid cells (henceforth called blocks).

\section{Data collection}

Sampling was performed between August 2009 and September 2009. Wood samples were taken using a sterilised $10 \mathrm{~mm}$ drill, with the exception of decay class 5 logs that were sampled by a sterilised soil corer (diameter $4 \mathrm{~cm}$ ). The decay class 5 logs were covered by bryophytes, which were removed before sampling and thus only woody material was included in sample. Five sub-samples were obtained per log (Figure 1), and sub-samples were pooled before analyses. Decay class 5 logs were often broken to short pieces, and in some cases it was not possible to obtain five sub-samples. The minimum number of sub-samples obtained per log was three.

Soil core samples were taken from litter/humus layers using a sterilised soil corer (diameter $4 \mathrm{~cm}$ ) on both sides of the sample logs, right below the drilling points. Hence, altogether 10 sub-samples next to decay class 1-4 logs and at least 6 beside decay class 5 logs were obtained (Figure 1). Living vegetation was removed from the soil surface before sampling, and mineral soil was excluded from the samples. Sub-samples of each sample log were pooled and homogenised in the laboratory.

Background soil cores also were taken from the study site at locations where dead wood was not nearby (distance to the nearest log at least $3 \mathrm{~m}$ ). Altogether, 10 background soil samples were collected, each of them consisting of 10 sub-samples, which were taken via the same sampling strategy as the main sampling (Figure 1). In each of the four additional Norway spruce-dominated managed

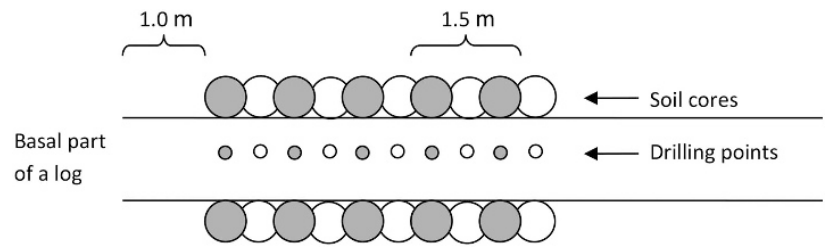

Figure 1 Strategy used for wood and soil sampling in the main study and in the methodological study. Filled symbols represent sub-samples that were combined, mixed and analysed (pooled samples 1). White symbols represent a new set of sub-samples, which were also combined, mixed and analysed (pooled samples 2), to test the amount of variation due to sampling errors and biological variation in fungal communities. In the methodological study, sub-samples in grey also were analysed separately. forests, we collected 3 background soil samples using the same sampling strategy.

To examine the sampling error related to our methods, one log from decay class 2 (sample log number 18) and one log from decay class 4 (number $64)$ were chosen. For these logs, in addition to the application of the pooling described above (to be called 'pooled samples 1'), sawdust and soil from individual sub-samples were also treated as independent samples, and thus homogenised and sequenced separately. In addition, for both of these two logs, new pooled samples were prepared by mixing another set of sub-samples, taken at an $\sim 10$ $\mathrm{cm}$ distance from the original ones (to be called 'pooled samples 2'). Furthermore, for 'pooled soil sample 1' we replicated DNA extraction and sequencing, that is, we took two samples for analyses from pooled and homogenised soil samples.

All dead wood samples were stored at $-20^{\circ} \mathrm{C}$ until pre-treatment and DNA extraction. Soil samples were stored at $+4{ }^{\circ} \mathrm{C}$ and sieved through a $2.8-\mathrm{mm}$ sieve as soon as possible but no later than 1 month after collecting. After that, soil samples were kept frozen $\left(-20^{\circ} \mathrm{C}\right)$ until DNA extraction.

\section{Stable isotope analyses}

All pooled wood and soil samples were analysed for $\delta^{13} \mathrm{C}$ and $\delta^{15} \mathrm{~N}$ by combustion under excess oxygen in an elemental analyser (EA, Costech 4010, Costech Analytical Technologies Inc., Valencia, CA, USA) connected in continuous-flow mode to an isotope ratio mass spectrometer (IRMS, Finnigan Delta Plus XP, Thermo Fisher Scientific, Waltham, MA, USA). We used 6-18 mg of a sample for the analysis, depending on the sample's $\mathrm{N}$ percentage. The standard deviation derived from repeated analyses of reference materials was smaller than $0.2 \%$ for $\delta^{13} \mathrm{C}$ and smaller than $0.3 \%$ for $\delta^{15} \mathrm{~N}$. We expressed the isotope signature in the delta notation $\delta^{13} \mathrm{C}=$ $\left(R_{\text {sample }} / R_{\text {standard }}-1\right) \times 1000(\%)$ relative to the international standard, which is VPDB 'Vienna Pee Dee Belemnite' for carbon and atmospheric $\mathrm{N}_{2}$ for nitrogen.

\section{DNA extraction}

Pooled dead wood samples of DC 1-4 were prepared by taking a spoonful of material from each subsample, adding sterile water (wood/water mixture of $\sim 20 \mathrm{ml}$ ) and mixing using a Pro250 Homogenizer (Pro Scientific, Oxford, CT, USA). Extra water was removed by centrifuging samples at 9000 r.p.m. for 3 min. Samples were kept on ice before and after homogenisation, after which DNA extraction was started immediately. DNA extraction from 150 to $250 \mathrm{mg}$ (fresh weight) samples was carried out using a PowerSoil DNA Isolation Kit (MoBio Laboratories, Carlsbad, CA, USA) according to the manufacturer's instructions with the following modifications: cell 
lysis was performed using a MoBio vortex adapter for $15 \mathrm{~min}$ and incubating for $30 \mathrm{~min}$ at $60^{\circ} \mathrm{C}$.

DNA extraction from the soil samples and heavily decayed wood samples (decay class 5) were performed with the same commercial kit (PowerSoil DNA Isolation Kit, MoBio) following the standard protocol with slight modifications: cell lysis was performed using a Fast Prep homogenizer (MP Biomedicals, Santa Ana, CA, USA) three times for $20 \mathrm{~s}$ at $4 \mathrm{~m} \mathrm{~s}^{-1}$ and incubating for $30 \mathrm{~min}$ at $65^{\circ} \mathrm{C}$.

\section{Polymerase chain reaction}

DNA samples were amplified with 454-fusion primers Adapter B/ITS3 and ITS4/6-bp tag/ Adapter A (Rajala et al., 2015), targeting the fungal rDNA ITS2 region. Polymerase chain reaction (PCR) mixes contained $9.9 \mu \mathrm{l}$ sterile water, $5 \mu \mathrm{l} 5 \times$ Phusion GC buffer (Thermo Fisher Scientific), $0.5 \mu \mathrm{l}$ dNTP mix (10 mM), $1.2 \mu \mathrm{l}$ of each primer $(8 \mu \mathrm{M}), 0.8 \mu \mathrm{l}$ DMSO, $0.2 \mu \mathrm{l}$ Phusion DNA Polymerase (Thermo Fisher Scientific) and $1 \mu \mathrm{l}$ DNA template, in a final volume of $20 \mu \mathrm{l}$. The optimal number of PCR cycles was tested for each sample to reach clearly visible but relatively weak bands in agarose gel ( $5 \mu \mathrm{l}$ of PCR product). When needed, dead wood samples were further purified with polyethylene glycol precipitation (Vainio et al., 1998), and soil samples were diluted 1:4 or 1:3. Final amplification was then performed using the following cycling conditions: $30 \mathrm{~s}$ at $98^{\circ} \mathrm{C} ; 20-28$ cycles of $10 \mathrm{~s}$ at $98^{\circ}$ C, $30 \mathrm{~s}$ at $55^{\circ} \mathrm{C}$ and $30 \mathrm{~s}$ at $72^{\circ} \mathrm{C}$; and a final extension at $72{ }^{\circ} \mathrm{C}$ for $5 \mathrm{~min}$.

PCR products were purified with AMPure (Agencourt AMPure XP PCR purification, Beckman Coulter, Brea, CA, USA), and concentrations were measured with a Qubit 2.0 fluorometer using a Quant-iT dsDNA HS Assay Kit (Invitrogen, Carlsbad, CA, USA). Bioanalyser (DNA1000 chip, Agilent Technologies, USA) was further used to ensure the quality of purified PCR products.

\section{4 sequencing}

Sequencing of the tagged amplicons was performed at the DNA Sequencing and Genomics Laboratory (Institute of Biotechnology, University of Helsinki, Finland) using a Genome Sequencer FLX Titanium XL+ System (454 Life Sciences Roche, Branford, CT, USA). The raw sequence data of dead woodinhabiting-taxa are archived at NCBI (National Center for Biotechnology Information, Bethesda, MD, USA) BioProject ID PRJNA341814.

\section{Bioinformatics analysis}

Sequence data were processed using the 'mothur' software package v. 1.34 (Schloss et al., 2009), following a previously described standard operating procedure (Schloss et al., 2011), with some modifications. Raw data (921674 reads) were subjected to a trimming step, where primers and barcodes were removed. Sequences were likewise trimmed if they: (i) did not contain correct primer and barcode sequences (pdiff $=0$, bdiff $=0$ ); (ii) were $<200 \mathrm{bp}$ in length; (iii) had homopolymers $>8 \mathrm{bp}$ in length; (iv) had ambiguous bases (maxambig $=0$ ); or (v) did not reach an average quality score of 35 using a 50-bp sliding window (qwindowaverage $=35$, qwindowsize $=50$ ). Potential chimeric sequences were identified and removed from unique sequences by UCHIME implemented in mothur (Edgar et al., 2011) using the UNITE/INSD ITS2-only UCHIME reference dataset v. 7 as a reference (Nilsson et al., 2015). Sequences that were part of larger fragments were clustered (frag.clust), and pairwise distances were calculated (cut-off $=0.25$, gapopen $=-1$ ). The sequence data were clustered into operational taxonomic units (OTUs) with a cut-off level of 0.03 using a nearest-neighbour algorithm. Singletons (that is, OTUs represented by only one sequence) were removed. OTUs were taxonomically assigned using the blast algorithm and the UNITE/INSD dataset v. 7 as a reference (Kõljalg et al., 2013). Of the 2381 OTUs, three were identified as plants and 67 as Protista and were removed. The remaining sequence data consisted of 290502 reads. These data were normalised by randomly selecting a subset of sequences, with their number set to the minimum of the number of sequences available for either wood or soil in each wood-soil sample pair. All soil background samples from the main study site and managed forest were normalised to contain the same number of sequences. Samples collected for methodological question were normalised so that each separate soil core had an equal number of sequences and together had the same number of samples as the pooled soil samples.

\section{Statistical analysis}

Variation of fungal communities was visualised by non-metric multidimensional scaling (NMDS) using meta-MDS of the vegan library (Oksanen et al., 2013) in R (R_Development_Core_Team, 2013). Threedimensional NMDS ordinations were performed with relative abundance (RA) data using the BrayCurtis distance measure and to reach the lowest stress, with the loop replicated 20 times with a maximum number of 80 starts.

We compared fungal communities among different sample groups in terms of their species richness and community composition. Our samples represented the following 12 groups: dead wood samples from DC 1-5 (groups 1-5); soil samples acquired around dead wood samples of DC 1-5 (groups 6-10); background soil samples from the main study site (group 11); and background soil samples from managed forest sites (group 12). For species richness, we performed a linear regression where the response variable was the log-transformed number of OTUs identified for each sample, and the explanatory variables were (1) the log-transformed number of 
sequences (a continuous covariate, to control for variation in sequencing depth (Tedersoo et al., 2014)) and (2) the sample group (a categorical variable). To compare community composition between sample groups, we computed Bray-Curtis dissimilarity indices for all pairs of samples within groups and between groups, using both relative sequence counts as well as presence/absence data. To test whether fungal communities between two groups were different, we computed the difference $r=\mathrm{BC}_{\mathrm{B}}-\mathrm{BC}_{\mathrm{W}}$, where $\mathrm{BC}_{\mathrm{W}}$ is the mean withingroup dissimilarity (average between the two groups) and $\mathrm{BC}_{\mathrm{B}}$ is the mean between-group similarity. We compared the value of $r$ to its null distribution derived using a randomisation approach, in which we randomly permuted the group labels among the samples. We note that this approach is similar to a PERMANOVA analysis (Anderson, 2001).

To examine in more detail a connection between soil and wood, we assessed if the fungal communities were more similar within each pair of dead wood samples and adjacent soil samples than expected by random. These analyses were conducted separately for each decay class. For this, we computed Bray-Curtis dissimilarity indices between all pairs of soil and dead wood samples and computed the difference $r=\mathrm{BC}_{\mathrm{B}}-\mathrm{BC}_{\mathrm{W}}$, which measures the similarity difference between pairs of dead wood samples and non-adjacent soil samples $\left(\mathrm{BC}_{\mathrm{B}}\right)$ and pairs of dead wood samples and adjacent soil samples $\left(\mathrm{BC}_{\mathrm{W}}\right)$. To examine whether similarity between wood and soil extended to some distance beyond the immediate vicinity of the log (that is, to assess the possible effects of spatial autocorrelation), we repeated the above analysis so that we computed the similarity difference between pairs of dead wood samples and soil samples taken in different $25 \times 25 \mathrm{~m}$ blocks and pairs of dead wood samples and soil samples taken within the same blocks. For both cases, we derived the null distribution of $r$ using a similar randomisation approach as described above, this time randomly permuting the unit identities for the wood samples.

\section{Results}

Fungal species richness

Altogether we observed 1990 OTUs. However, as expected, most of them were rare: in the pooled data, the 30 most abundant OTUs yielded $50 \%$ of all sequences. On average the sequencing depth was 5009 sequences per sample. Soil fungal communities were more species rich compared to wood communities (Figure 2a). Species richness in dead wood increased monotonically with decay class $(P<0.001)$, whereas the species richness in the soil beside the logs stayed constant. In the last decay class (5) the fungal species richness from dead wood almost equalled with the species richness from soil (Figure 2a). There was no difference in species richness between the additional managed forest soils and the soil from the unmanaged forest site, neither between the soil samples collected beside decaying logs versus the background samples obtained far away from logs within the unmanaged forest site $(P=0.9)$. The most drastic increase in species richness in dead wood occurred from recently and moderately decayed wood (DC 1-3) to heavily decayed wood (decay class 5) and soil (Figure 2a). As expected, the measured species richness also increased with sequencing depth $(P<0.001)$.

\section{Fungal community composition}

The number of OTUs unique to soil was 793, the number of OTUs unique to wood was 589, and the number of OTUs found from both habitats was 608 (Table 1). Species unique to wood were, for example, the wood decayers Fomitopsis pinicola, Antrodia serialis, Phellopilus nigrolimitatus and Phellinus a

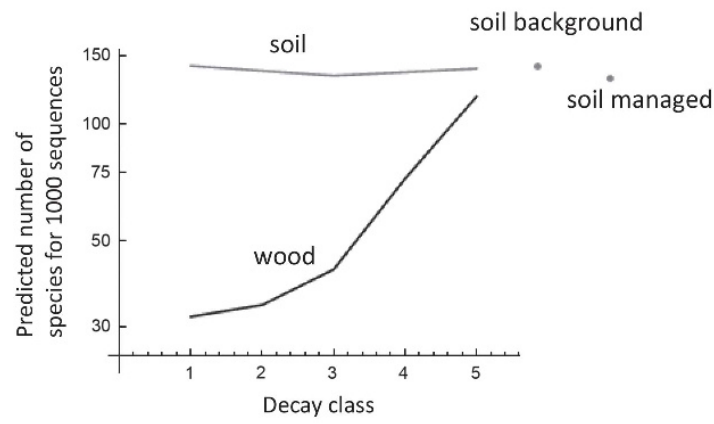

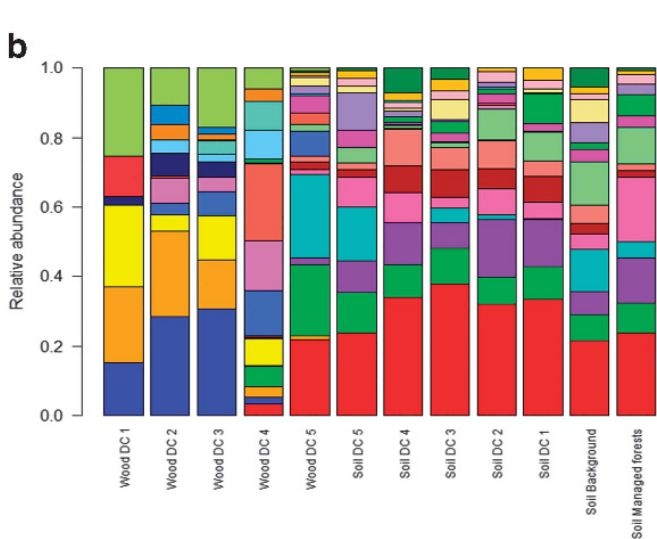

ㅁ Phellopilus nigrolimitatus Phellinus ferrugineovelutinus ․ Atractiellales Exidiasp. Tomentella terrestris G Hyphodontia abieticola $\square$ Helotiales sp. 口 Byssocorticium sp. Lactarius rufus Aphanobasidium pseudotsugae - Russula emetica - Avachytrium plate - Phellinus viticola Hyphodontia pallidula - Russula decolorans Agaricales sp. ㅁ Piloderma fallax - Auriculariales ㅁ Mortierella humilis Antrodia serialis Gymnomyces Tylosporasp. ㅁ Heterobasidion parviporum

Figure 2 Species richness and species identity in wood and soil substrates. (a) The predicted fungal species richness in different substrates and (b) the RA of 30 most abundant operational taxonomic units in each substrate type. For constructing (a), the response variable in the underlying linear model was the log-transformed number of operational taxonomic units (OTUs) identified for each sample, and the explanatory variables were the log-transformed number of sequences (a continuous covariate) and the sample group (a categorical variable). 
Table 1 Fungal species found exclusively in soil, exclusively in dead wood, and in both substrate types

\begin{tabular}{lll}
\hline Unique to soil (793) & Both in soil and wood (608) & Unique to wood (589) \\
\hline Piloderma sp. (OTU 00094) & Piloderma sphaerosporum (OTU 00310) & Fomitopsis pinicola (OTU 00001) \\
Russula sp. (OTU 00048) & Heterobasidium parviporum (OTU 00003) & Antrodia serialis (OTU 00004) \\
Russula vesca (OTU 00178) & Tylospora sp. (OTU 00005) & Phellopilus nigrolimitatus (OTU 00006) \\
Tretomyces lutescens OTU 00211) & Gymnomyces monosporous (OTU 00011) & Phellopilus nigrolimitatus (OTU 00022) \\
Amanita sp. (OTU 00174) & Connopus acervatus (OTU 00017) & Phellinus viticola (OTU 00014) \\
Pseudotomentella sp. (OTU 00189) & Mortierella humilis (OTU 00009) & Phellopilus nigrolimitatus (OTU 00019) \\
Cortinarius caperatus (OTU 00180) & Auriculariales sp. (OTU 00029) & Exidia sp. (OTU 00037) \\
Cortinarius rubellus (OTU 00088) & Piloderma fallax (OTU 00024) & Atractiellales sp. (OTU 00033) \\
Rhodocollybia sp. (OTU 00128) & Agaricales sp. (OTU 00010) & Phellinis ferrugineovelutinus (OTU 00020) \\
Cortinarius traganus (OTU 00212) & Russula decolorans (OTU 00025) & Coniophora puteana (OTU 00007) \\
Trechisporales sp. (OTU 00308) & Hyphodontia pallidula (OTU 00012) & Basidioascus (OTU 00039) \\
Pseudotomentella humicola (OTU 00308) & Basidiodendron caesiocinereum (OTU 00012) & Pseudeurotiaceae sp. (OTU 00044) \\
Cortinarius sp. (OTU 00319) & Avachytrium platense (OTU 00015) & Sistotrema brinkmannii (OTU 00041) \\
Piloderma sphaerosporum (OTU 00310) & Russula emetical (OTU 00038) & Hyphoderma sp. (OTU 00055) \\
Mortierella sp. (OTU 00097) & Aphanobasidium pseudotsugae (OTU 00013) & Stereum sanguinolentum (OTU 00026) \\
\hline
\end{tabular}

The 15 most abundant species are listed, and the numbers in brackets indicate the total number of species found.

viticola, whereas species such as Piloderma sphaerosporum, Tylospora sp., Gymnomyces monosporus and Connopus avercatus as well as many Russula species were abundant in soil and decay class 5 logs (Table 1 and Figure 2b). Most of the species sharing between wood and soil occurred when dead wood logs were in decay class 4 and particularly decay class 5 logs. Fungi observed only in the soil were typically OTUs in ectomycorrhizal genera, such as Cortinarius, Amanita and some Piloderma species (Figure 2b).

In decay class 1 logs, the brown-rot fungi Fomitopsis pinicola and Antrodia serialis; white-rot fungi Heterobasidium parviporum, Phellopilus nigrolimitatus and Phellinus viticola; and saprotrophic Exidia sp. were the dominant species (Figure $2 b$ and Supplementary Table 1). In DC 2 and 3, the same species were common, with the exception of Exidia sp. In decay class 4 , fungal species richness clearly increased, and logs harboured fungal community which was a mixture of the OTUs found either from slightly decayed wood or soil: the aphyllophoroid saprotrophic fungi Basidiodendron caesiocinereum and Hyphodontia pallidula together with Agaricales sp. became common, but also mychorrhizal Piloderma sphaerosporum and Tylospora sp. were present. Thus, decay stage 4 had unique species pool (Figures 2b and 3a). In decay stage 5, the dominant species in dead wood changed to the mycorrhizal Piloderma sphaerosporum and Tylospora sp. and the saprotrophic Connopus acervatus. The latter species were common in the soil, as well (Figure 2b). Other species such as the saprotrophic Mortierella humilis and mycorrhizal Gymnomyces monosporus, Piloderma fallax and Russula decolorans were abundant in both soil and heavily decayed wood.

Some aphyllophoroid fungi (such as Basidiodendron and Hyphodontia sp.), were present in almost all the wood DC (excluding class 1) and they were additionally repeatedly found in the soil samples from beneath the logs. The latter aphyllophoroid species were extremely rare in the soil samples collected in the additional managed forest sites (Supplementary Table 1). All the wooddecomposing white- and brown-rot polypore fungal species were strictly limited to the wood in DC 1-4 (Supplementary Table 1).

In line with the observations made in the identities of the most common species, fungal communities differed between wood and soil, and logs of different DC hosted distinct wood-inhabiting communities (Figure 3a and Supplementary Figure S1). Soil fungal communities beside the logs of different DC overlapped most in the last (that is, 4-5) decay stages (Figures 2b and 3a). According to the Bray-Curtis dissimilarity values, fungal communities can be grouped as follows: (A) soil samples acquired near wood of DC 1-4; (B) background soil samples and soil samples acquired near wood of decay class 5; (C) wood samples of DC 1-4; and (D) wood samples of heavily decayed wood (that is, decay class 5). Within group C, there is a gradient such that wood samples from consecutive DC are more similar to each other than wood samples from non-consecutive DC (Supplementary Figure S1). The analyses based on presence/absence and abundance were largely concordant, suggesting robustness of the results.

We found soil- and wood-inhabiting communities to be locally more similar than expected by random, especially in the case of logs in DC 2-5 (Table 2). In other words, soil-inhabiting fungal communities were more similar to wood-inhabiting fungal communities if the soil core was acquired under the same log where the wood sample was acquired, than if the soils sample was acquired under a different log. The similarity between soil- and wood-inhabiting communities did not extend far beyond the immediate vicinity of the log, as we did not find evidence for increased similarity between samples acquired from the same $25 \times 25$ block. An exception here was given by samples obtained for decay class 5 , but even for 


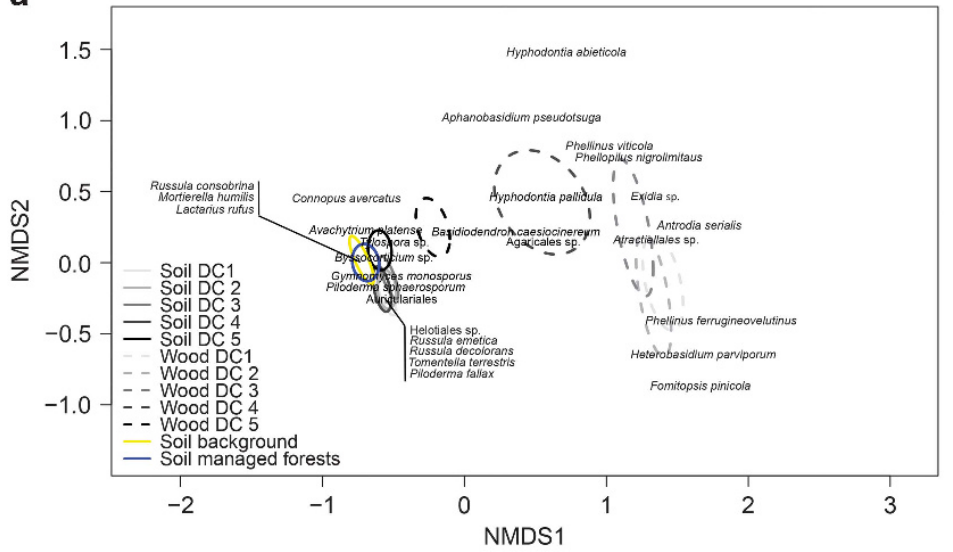

b

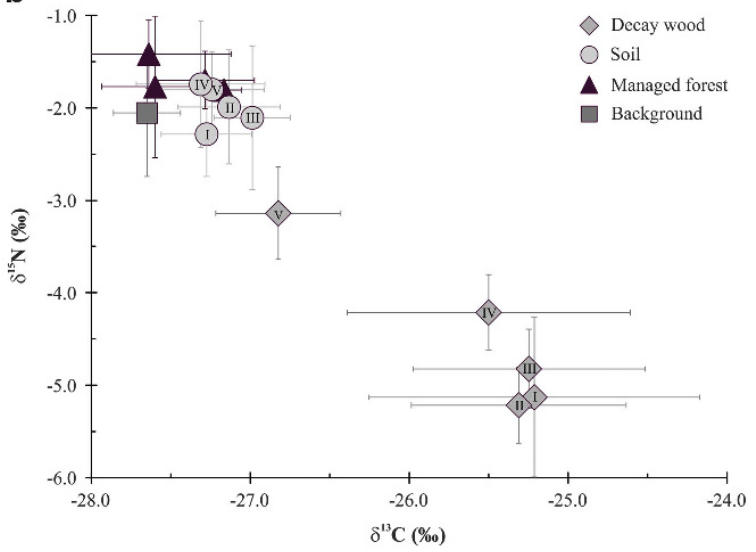

Figure 3 Community composition (a) and nitrogen and carbon stable isotope values (b) in decaying wood and soil. (a) A NMDS plot showing variation of fungal communities in logs from different DC (1-5) in soil adjacent to the logs, soil non-adjacent (soil background) and soil from the additional four managed forests. Ninety-five per cent confidence ellipses of each substrate type are based on the standard errors of the weighted average of sample scores. Species scores of the 30 most abundant operational taxonomic units are plotted to the ordination. (b) The variation in nitrogen and carbon stable isotope values in logs from different DC (I, II, III, IV and V), soil adjacent to the logs (grey circles with symbols I, II, III, IV and V), soil non-adjacent (grey square) and soil from the additional four managed forests (black triangles).

Table 2 Difference $(r)$ and its significance $(P)$ for Bray-Curtis dissimilarity indices between paired soil and wood samples compared to non-paired soil and wood samples

\begin{tabular}{|c|c|c|c|c|c|}
\hline & $D C 1$ & $D C 2$ & $D C 3$ & $D C 4$ & $D C 5$ \\
\hline \multirow[t]{2}{*}{ Log (RA) } & $r=0.001$ & $r=0.003$ & $r=0.008$ & $r=0.018$ & $r=0.158$ \\
\hline & $P=0.047$ & $P=0.038$ & $P=0.003$ & $P=0.021$ & $P<0.001$ \\
\hline \multirow[t]{2}{*}{ Log (PA) } & $r=0.003$ & $r=0.007$ & $r=0.011$ & $r=0.019$ & $r=0.109$ \\
\hline & $P=0.071$ & $P=0.015$ & $P=0.003$ & $P<0.001$ & $P<0.001$ \\
\hline \multirow[t]{2}{*}{ Block (RA) } & $r=-0.001$ & $r=0.001$ & $r=0.001$ & $r=0.011$ & $r=0.059$ \\
\hline & $P=0.622$ & $P=0.201$ & $P=0.154$ & $P=0.365$ & $P=0.040$ \\
\hline \multirow[t]{2}{*}{ Block (PA) } & $r=-0.009$ & $r=-0.004$ & $r=0.0009$ & $r=0.009$ & $r=0.045$ \\
\hline & $P=0.630$ & $P=0.881$ & $P=0.070$ & $P=0.375$ & $P=0.030$ \\
\hline
\end{tabular}

In the log-level analyses, a soil and wood sample was considered paired if the soil sample was acquired right under the log from which the wood sample was acquired, whereas in other cases the soil and wood samples were considered as non-paired. In the Block-level analyses, a soil and wood sample was considered paired if the soil sample was acquired from the same block (a $25 \mathrm{~m} \times 25 \mathrm{~m}$ area) but under a different log from which the wood sample was acquired, whereas wood and soil samples that originated from different block were considered as non-paired. The analyses have been conducted separately for DC $1-5$. Statistics were calculated for OTU data, measured either as RA or as presence-absence (PA). Cases with $P<0.05$ are emphasised with bold font.

this case the similarity at the log-level was much higher than at the block-level (Table 2).

\section{Stable isotopes}

The isotope signals of decaying wood deviated from those observed from the soil organic layer (Figure $3 \mathrm{~b}$ ). The decaying logs of DC 1-4 had, on average, $3 \%$ more negative $\delta^{15} \mathrm{~N}$ values relative to the soil organic matter, whereas decay class 5 was more similar to the soil in this respect. Nitrogen concentration of logs in decay class 1-4 was very low, but increased in the late decay phase (Supplementary Figure S2). The average $\delta^{15} \mathrm{~N}$ value of the soil organic matter beside decaying logs ranged between $-1.7 \%$ and $-2.3 \%$, thus being similar to the soil background $\delta^{15} \mathrm{~N}$ value of $-2.1 \%$. The average soil $\delta^{15} \mathrm{~N}$ values of the studied unmanaged forest were very similar to those measured in the soils from the managed forests $(-1.7 \pm 0.2 \%, n=4)$. The average $\delta^{13} \mathrm{C}$ values of the dead wood samples in DC 1-4 ranged from $-25.5 \%$ \pm 0.89 to $-25.2 \%$ \pm 1.04 , whereas decay class 5 , with a $\delta^{13} \mathrm{C}$ value of $-26.7 \pm 0.58$, was close to the $\delta^{13} \mathrm{C}$ values measured for the soil organic matter (Figure 3b).

\section{Methodological comparison}

Comparison of NMDS of fungal communities in pooled soil and wood samples with that of separate sub-samples showed that the pooled samples were located in the centre of the separate sub-samples in the ordination plot (Supplementary Figure S3). The NMDS of pooled samples 2 was similar to that of pooled samples 1. DNA analyses were performed twice for pooled soil samples 1 (figure 1a and b). 
The results were nearly identical, indicating that the sampling for DNA analysis was highly replicable and contained only a small sampling error compared to the biologically relevant signal in the data.

\section{Discussion}

Dead wood contributed much to the overall fungal species diversity, as one-third of all species recorded in our study were found to be exclusively inhabit wood. Therefore, in concordance with numerous previous studies (for example, Siitonen, 2001), our results indicate that lack of dead wood in managed Norway spruce stands is a threat for a large part of the local fungal diversity, and especially polypores. Furthermore, our results show that the occurrences of some soil species are triggered by the presence of heavily decayed dead wood, which is almost absent in managed boreal Norway spruce forests (Siitonen, 2001; Ihalainen and Mäkelä, 2009).

Results from several studies have shown that some soil-inhabiting fungal species occur on dead wood in advanced stages of decay (Renvall, 1995; Rajala et al., 2012, 2015; Ottosson et al., 2014), and that conversely, some wood-decaying fungi are able to colonise soil (Boddy, 1993, 1999; Lindahl et al., 2007). Our study confirms these previous findings and provides a deeper understanding on when and how soil- and wood-inhabiting communities interact. During the decay of a Norway spruce log, the fungal community in the log becomes increasingly species rich and more similar to fungal communities found from soil. According to Rinne et al. (2016), the highest biological activity was measured in the decay stage 4 , which is a decay stage where we observed unique species pool and wide variation in fungal community. In the late stages of wood decay (4-5), species typically found from soil become highly abundant in dead wood. The fungal communities in soil near decaying logs do not differ much from fungal communities in background soils, except for logs at the last decay stages. However, there is a local connection between wood and soil: the fungal community in soil under a decaying log resembles the fungal community of that log more than fungal communities of other logs in similar decay stages.

The increase in fungal species richness in wood during the decay is associated with the gain of mycorrhizal and some soil-saprotroph species. The mycorrhizal species which were abundant within dead wood were Gymnomyces monosporus, Piloderma fallax, P. sphaerosporum, Tylospora sp., and Russula decolorans. Tylospora sp. exhibits lignocellulose-degrading laccase enzyme activity (Velmala et al., 2014), which indicates that apart from mycorrhizal capabilities, it has wood-decaying capabilities. In the same line, Wallander et al. (2010) showed that Tylospora sp. are very efficient in colonising soil substrates, especially when the amount of available carbon is high. As recently argued by Lindahl and Tunlid (2015), the role of mycorrhizal fungi in decomposing the soil organic matter has been largely overlooked thus far. Our results support the idea that some mycorrhizal fungi are capable of utilising organic resources. The species Mortierella humilis, which is a typical species from soil (Lindahl et al., 2007), was found to be as abundant in heavily decayed wood as it was in soil. Thus, decaying wood is an important habitat for some 'soil' saprotropic fungi and fungal communities became similar to soil-inhabiting fungal communities in the late stages of decay (4-5). In the heavily decayed wood, soil saprotropic fungi and mycorrhizal fungi are strong competitors (Holmer and Stenlid, 1997) and they replace white- and brown-rotting fungi as substrate physiochemical properties resemble soil.

The presence of decaying logs locally influenced soil fungal communities, as some fungal species occurred in soil only when decaying wood was present at the surface (particularly beside logs of DC 2-5). For instance, some wood-decaying aphyllophoroid fungi of the genera Basidiodendron and Hyphodontia were present in almost all the soil samples taken beneath the decaying logs. In terms of fruitbody records, these species are known to only occur on dead wood (Kotiranta et al., 2009). Given that our study does not involve fruitbody data and that these wood-decaying aphyllophoroid fungal species have not been found in soil previously, the functional role of these species on soil remains unclear. For example, the DNA collected in the soil beneath the logs may have belonged to deposited spores. Another local effect that decaying logs had on the soil surface was that the occurrences of some mycorrhizal species seemed to be triggered by the presence of highly decayed wood. For instance, the relative abundance of the mycorrhizal Piloderma sphaerosporum species was highest in soil adjacent to heavily decayed logs. In addition to being an additional source of nutrients, logs in late decay phase may provide more stable moisture content to the soil surface (Rajala et al., 2012), offering beneficial habitat conditions for some mycorrhizal species. Surprisingly, even if the wood-decaying cord-forming basidiomycetes are known to spread to soil via their cords (Boddy, 1993, 1999), our data did not show strong signals of the presence of cordforming basidiomycetes in soil being triggered by the presence of dead wood. The latter result might be due to the fact that our samples were collected only once in autumn, which might not be the optimal time for detecting the mycelial growth of this group of species.

Our stable isotope analyses indicated that fungi inhabiting wood in late decay stages are responsible of transporting $\mathrm{N}$ from external sources to wood. During the early decay phase, when fungal communities are most different from those in the forest soil and wood $\mathrm{N}$ content is very low $\left(0.5-0.6 \mathrm{mg} \mathrm{N} \mathrm{g}^{-1}\right.$ d.w.), fungi do not transfer nitrogen from soil in 
significant amounts. In the late decay phase instead, when fungal communities in dead wood highly resembled soil communities and wood $\mathrm{N}$ content was increased to $7 \mathrm{mg} \mathrm{N} \mathrm{g}^{-1}$ d.w., the stable isotope signals were very similar to those measured from soil organic matter. This can be explained by transfer of ${ }^{15} \mathrm{~N}$ - enriched nitrogen compounds from forest soil to decaying wood where $\mathrm{N}$ consequently increases. In addition, ${ }^{15} \mathrm{~N}$ enrichment in highly decayed wood can be due to mycorrhizal transfer of ${ }^{15} \mathrm{~N}$-depleted $\mathrm{N}$ to host plant (Hobbie and Hobbie, 2006), since the higher levels of $\delta^{15} \mathrm{~N}$ coincided with the dead wood colonisation of mycorrhizal fungi. Because we observed increasing wood $\mathrm{N}$ content simultaneously with ${ }^{15} \mathrm{~N}$ enrichment, the transfer of $\mathrm{N}$ to host plants cannot be the only factor contributing to observed isotope values. The increase in the ${ }^{15} \mathrm{~N}$ values may also be explained by asymbiotic $\mathrm{N}_{2}$ fixation in decaying wood, but as discussed by Rinne et al. (2016), ${ }^{15} \mathrm{~N}$ values would be even higher if $\mathrm{N}_{2}$ fixation alone was a source of external nitrogen. Simultaneously decreasing ${ }^{13} \mathrm{C}$ values also indicate that mycorrhizal fungi, which gain recently assimilated ${ }^{13} \mathrm{C}$-depleted $\mathrm{C}$ from host plant, contribute to $\mathrm{C}$ dynamics in heavily decayed wood and the import of photosynthates may accelerate the wood decay. The external carbon and nutrient transportation to wood might have important consequences for nutrient cycling, as the activity of wood-decomposing fungi is stimulated when $\mathrm{N}$ availability is enhanced (Bebber et al., 2011). Stable isotope analyses of fungal fruit bodies in dead wood would be helpful for disentangling which fungal species are responsible of nutrient transport from soil to dead wood (Mayor et al., 2009).

We conclude that soil and wood-inhabiting fungal communities interact at all decay phases of wood, with significant implications for forest nutrient transportation. Our results confirm that decaying wood has an important contribution to the overall fungal diversity because a large fraction of all species were found to exclusively inhabit wood. Thus, wood specialised species are lost from managed forests where decaying wood is absent. We have shown interaction between soil and wood-inhabiting fungi and we suggest that transfer of carbon and nutrients by fungi has importance to wood decay process. Future challenge is to resolve the implications of nutrient transportation from soil to wood for the activity of wood-inhabiting fungal communities and the overall nutrient fluxes in forest ecosystems.

\section{Conflict of Interest}

The authors declare no conflict of interest.

\section{Acknowledgements}

We are thankful for the technical staff of the Natural Resources Institute Finland; H Ali-Kovero at the University of Helsinki for skilful help in sampling and in the laboratory; and J Chen and E Hobbie at the University of New Hampshire, Stable Isotope Laboratory for isotope analyses. We thank three anonymous reviewers for most helpful comments. Financial support was provided by the Academy of Finland (project 292899 to RM, 250444 to OO, 257748 to DS and 292967 to TP) and the Research Council of Norway (CoE Grant No. 223257 to OO and NA).

\section{References}

Abrego N, Salcedo I. (2013). Variety of woody debris as the factor influencing wood-inhabiting fungal richness and assemblages: Is it a question of quantity or quality? For Ecol Manag 291: 377-385.

Anderson MJ. (2001). A new method for non-parametric multivariate analysis of variance. Austral Ecol 26: $32-46$.

Bebber DP, Watkinson SC, Boddy L, Darrah PR. (2011). Simulated nitrogen deposition affects wood decomposition by cord-forming fungi. Oecol 167: 1177-1184.

Boddy L. (1993). Saprotrophic cord-forming fungi: warfare strategies and other ecological aspects. Mycol Res 97: 641-655.

Boddy L, Watkinson SC. (1995). Wood decomposition, higher fungi, and their role in nutrient redistribution. Can J Bot 73: 1377-1383.

Boddy L. (1999). Saprotrophic cord-forming fungi: meeting the challenge of heterogeneous environments. Mycologia 91: 13-32.

Boddy L. (2000). Interspecific combative interactions between wood-decaying basidiomycetes. FEMS Microbiol Ecol 31: 185-194.

Boddy L, Frankland JC, West P. (2008). Ecology of Saprotrophic Basidiomycetes. Academic Press: London.

Buée M, Reich M, Murat C, Morin E, Nilsson RH, Uroz S et al.. (2009). 454 pyrosequencing analyses of forest soils reveal an unexpectedly high fungal diversity. N Phytol 184: 449-456.

Edgar RC, Haas BJ, Clemente JC, Quince C, Knight R. (2011). UCHIME improves sensitivity and speed of chimera detection. Bioinformatics 27: 2194-2200.

Edman M, Jonsson BG. (2001). Spatial pattern of downed logs and wood-decaying fungi in an old-growth Picea abies forest. J Veget Sci 12: 609-620.

Ferguson BA, Dreisbach TA, Parks CG, Filip GM, Schmitt CL. (2003). Coarse-scale population structure of pathogenic Armillaria species in a mixed-conifer forest in the Blue Mountains of northeast Oregon. Can J For Res 33: 612-623.

Fridman J, Walheim M. (2000). Amount, structure, and dynamics of dead wood on managed forestland in Sweden. For Ecol Manag 131: 23-36.

Gessner MO, Swan CM, Dang CK, McKie BG, Bardgett RD, Wall DH et al.. (2010). Diversity meets decomposition. Trends Ecol Evol 25: 372-380.

Grove SJ. (2001). Extent and composition of dead wood in Australian lowland tropical rainforest with different management histories. For Ecol Manag 154: 35-53.

Hobbie JE, Hobbie EA. (2006). 15N in symbiotic fungi and plants estimates nitrogen and carbon flux rates in Arctic tundra. Ecology 87: 816-822. 
Holmer L, Stenlid J. (1997). Competitive hierarchies of wood decomposing basidiomycetes in artificial systems based on variable inoculum sizes. Oikos 79: 77-84.

Hotanen J-P, Nousiainen H, Mäkipää R, Reinikainen A, Tonteri T. (2008). Metsätyypit - Opas Kasvupaikkojen Luokitteluun. Metsäkustannus, Karisto: Hämeenlinna.

Hättenschwiler S, Tiunov AV, Scheu S. (2005). Biodiversity and litter decomposition in terrestrial ecosystems. Ann Rev Ecol Evol Syst 36: 191-218.

Ihalainen A, Mäkelä H. (2009). Kuolleen puuston määrä Etelä- ja Pohjois-Suomessa 2004-2007. Metsätieteen aikakauskirja 1/2009: 35-56.

Kebli H, Brais S, Kernaghan G, Drouin P. (2012). Impact of harvesting intensity on wood-inhabiting fungi in boreal aspen forests of Eastern Canada. For Ecol Manag 279: 45-54.

Kõljalg U, Nilsson RH, Abarenkov K, Tedersoo L, Taylor AFS, Bahram M et al.. (2013). Towards a unified paradigm for sequence-based identification of fungi. Mol Ecol 22: 5271-5277.

Kotiranta H, Saarenoksa R, Kytövuori I. (2009). Aphyllophoroid fungi of Finland. A check-list with ecology, distribution, and threat categories. Norrlinia 19: 1-223.

Kubartová A, Ottosson E, Dahlberg A, Stenlid J. (2012). Patterns of fungal communities among and within decaying logs, revealed by 454 sequencing. Mol Ecol 21: 4514-4532.

Laiho R, Prescott CE. (2004). Decay and nutrient dynamics of coarse woody depris in northern coniferous forests: a synthesis. Can J For Res 34: 763-777.

Lindahl BD, Ihrmark K, Boberg J, Trumbore SE, Högberg P, Stenlid J et al.. (2007). Spatial separation of litter decomposition and mycorrhizal nitrogen uptake in a boreal forest. N Phytol 173: 611-620.

Lindahl BD, Tunlid A.. (2015). Ectomycorrhizal fungipotential organic matter decomposers, yet not saprotrophs. N Phytol 205: 1443-1447.

Mahmood S, Finlay RD, Fransson A-M, Wallander $\mathrm{H}$. (2003). Effects of hardened wood ash on microbial activity, plant growth and nutrient uptake by ectomycorrhizal spruce seedlings. FEMS Microbiol Ecol 43: 121-131.

Mayor JR, Schuur EAG, Henkel TW. (2009). Elucidating the nutritional dynamics of fungi using stable isotopes. Ecol Lett 12: 171-183.

Mäkinen H, Hynynen J, Siitonen J, Sievänen R. (2006). Predicting the decomposition of Scots pine, Norway spruce and birch stems in Finland. Ecol Appl 16: 1865-1879.

Nilsson RH, Tedersoo L, Ryberg M, Kristiansson E, Hartmann M, Unterseher M et al.. (2015). A comprehensive, automatically updated fungal ITS sequence dataset for reference-based chimera control in environmental sequencing efforts. Microbes Environ 30: 145-150.

Oksanen J, Blanchet FG, Kindt R, Legendre P, Minchin PR, O'Hara RB et al.. (2013), Vegan: ordination methods, diversity analysis and other functions for community and vegetation ecologists. Community Ecology Package Vegan. Available at: https://cran.r-project.org, https://github.com/vegandevs/vegan.

Ottosson E, Nordén J, Dahlberg A, Edman M, Jönsson M, Larsson K-H et al.. (2014). Species associations during the succession of wood-inhabiting fungal communities. Fungal Ecol 11: 17-28.

Ovaskainen O, Schigel D, Ali-Kovero H, Auvinen P, Paulin L, Hottola J. (2013). Combining high-throughput sequencing with fruit-body surveys reveals contrasting life-history strategies in fungi. ISME J 7: 1696-1709.

Peltoniemi M, Penttilä R, Mäkipää R. (2013). Temporal variation of polypore diversity based on modelled dead wood dynamics in managed and natural Norway spruce forests. For Ecol Manag 310: 523-530.

Philpott TJ, Prescott CE, Chapman WK, Grayston SJ. (2014). Nitrogen translocation and accumulation by a cordforming fungus (Hypholoma fasciculare) into simulated woody debris. For Ecol Manag 315: 121-128.

R_Development_Core_Team. (2013). R: a language and environment for statistical computing. Avaialble at: http://www.R-project.org.

Rajala T, Peltoniemi M, Pennanen T, Mäkipää R. (2012). Fungal community dynamics in relation to substrate quality of decaying Norway spruce (Picea abies [L.] Karst.) logs in boreal forests. FEMS Microbiol Ecol 81: 494-505.

Rajala T, Tuomivirta T, Pennanen T, Mäkipää R. (2015). Habitat models of wood-inhabiting fungi along a decay gradient of Norway spruce logs. Fungal Ecol 18: 48-55.

Ranius T, Kindvall O, Kruys N, Jonsson BG. (2003). Modelling dead wood in Norway spruce stands subject to different management regimes. For Ecol Manag 182: 13-29.

Rayner ADM, Boddy L. (1988). Fungal Decomposition of Wood : Its Biology and Ecology. Wiley: Chichester.

Renvall P. (1995). Community structure and dynamics of wood-rotting basidiomycetes on decomposing conifer trunks in northern Finland. Karstenia 35: 1-51.

Rinne KT, Rajala T, Peltoniemi K, Chen J, Smolander A, Mäkipää R. (2016). Accumulation rates and sources of external nitrogen in decaying wood in a Norway spruce dominated forest. Funct Ecol 31: 530-541.

Schloss P, Westcott S, Ryabin T, Hall J, Hartmann M, Hollister E et al.. (2009). Introducing mothur: opensource, platform-independent, community-supported software for describing and comparing microbial communities. Appl Environ Microbiol 75: 7537-7541.

Schloss PD, Gevers D, Westcott SL. (2011). Reducing the effects of PCR amplification and sequencing artifacts on 16S rRNA-based studies. PLoS One 6: e27310.

Siitonen J. (2001). Forest management, coarse woody debris and saproxylic organisms: Fennoscandian boreal forests as an example. Ecol Bull 49: 11-41.

Smith SE, Read DJ. (2008). Mycorrhizal Symbiosis, 3rd edn. Academic Press: London.

Stokland JN, Siitonen J, Jonsson BG. (2012). Biodiversity in Dead Wood. Cambridge University Press: Cambridge.

Tedersoo L, Kõljalg U, Hallenberg N, Larsson K-H. (2003). Fine scale distribution of ectomycorrhizal fungi and roots across substrate layers including coarse woody debris in a mixed forest. N Phytol 159: 153-165.

Tedersoo L, Bahram M, Põlme S, Kõljalg U, Yorou NS, Wijesundera $\mathrm{R}$ et al.. (2014). Global diversity and geography of soil fungi. Science 346: 1078.

Vainio EJ, Korhonen K, Hantula J. (1998). Genetic variation in Phlebiopsis gigantea as detected with random amplified microsatellite (RAMS) markers. Mycol Res 102: 187-192.

Valentín L, Rajala T, Peltoniemi M, Heinonsalo J, Pennanen T, Mäkipää R. (2014). Loss of diversity in woodinhabiting fungal communities affects decomposition activity in Norway spruce wood. Front Microbiol 5: 230.

Wallander H, Johansson U, Sterkenburg E, Brandström Durling M, Lindahl BD. (2010). Production of ectomycorrhizal mycelium peaks during canopy 
closure in Norway spruce forests. $N$ Phytol 187: 1124-1134.

Watkinson S, Bebber D, Darrah P, Fricker M, Tlalka M, Boddy L (2006). The role or wood decay fungi in the carbon and nitrogen dynamics of the forest floor. In: Gadd GM (ed). Fungi in Biogeochemical Cycles. Cambridge University Press: Cambridge, p 469.

Wells JM, Boddy L. (2002). Interspecific carbon exchange and cost of interactions between basidiomycete mycelia in soil and wood. Funct Ecol 16: 153-161.

Velmala SM, Rajala T, Heinonsalo J, Taylor AFS, Pennanen T. (2014). Profiling functions of ectomycorrhizal diversity and root structuring in seedlings of Norway spruce (Picea abies) with fast- and slowgrowing phenotypes. N Phytol 201: 610-622. (i) () $\Theta$ This work is licensed under a Creative Commons Attribution-NonCommercialNoDerivs 4.0 International License. The images or other third party material in this article are included in the article's Creative Commons license, unless indicated otherwise in the credit line; if the material is not included under the Creative Commons license, users will need to obtain permission from the license holder to reproduce the material. To view a copy of this license, visit http://creativecommons.org/ licenses/by-nc-nd/4.0/

(C) The Author(s) 2017

Supplementary Information accompanies this paper on The ISME Journal website (http://www.nature.com/ismej) 